\title{
Cataegis, New Genus of Three New Species from the Continental Slope (Trochidae: Cataeginae New Subfamily)
}

\author{
James H. McLean \\ Los Angeles County Museum of \\ Natural History \\ 900 Exposition Blvd \\ Los Angeles, CA 90007, USA
}

\author{
James F. Quinn, Jr. \\ Florida Department of Natural \\ Resources \\ Bureau of Marine Research \\ 100 Eighth Ave., S.E. \\ St. Petersburg, FL 33701, USA
}

\begin{abstract}
Cataegis new genus, type species $C$. toreuta new species, is proposed to include three new species from continental slope depths $(200-2,000 \mathrm{~m})$ : the type species and C. meroglypta from the Gulf of Mexico to Colombia, and C. celebesensis from Makassar Strait, Indonesia. Important shell characters are the prominent spiral cords, non-umbilicate base, and oblique aperture. The radula is unique among the Trochidae in lacking the rachidian, having the first pair of laterals fused and uncusped, and the first marginals enlarged. The gill is the advanced trochid type with well-developed afferent membrane. These characters do not correspond to an available subfamily; the new subfamily Cataeginae is therefore proposed.
\end{abstract}

\section{INTRODUCTION}

The two hitherto unknown species of trochids described here from continental slope depths in the Caribbean Sea and Guif of Mexico were first examined by Quinn, who noted that shell characters of the two species are unlike those of any known genus of Trochidae. Epipodial and radular characters were later examined by McLean, who found a unique combination of radular features in one of the two species. A third member of the genus from slope depths in Indonesian waters was subsequently recognized by McLean in unidentified material received on loan from the Paris Museum. An unsuccessful search for a genus for these species prompted the present description of a new genus.

Although higher classification of Trochidae has been unsettled (Marshall, 1979), consideration of gill characters has led to new understanding (McLean, 1982), and a full review of higher classification of Trochacea is nearing completion by Hickman and McLean (in preparation). Full discussion of trochacean classification is deferred to that review. The new genus cannot be assigned to an existing trochid subfamily, necessitating the proposal of a new subfamily.

Institutional abbreviations used here are: ANSP (Academy of Natural Sciences, Philadelphia); FSBC I (Florida Department of Natural Resources, Bureau of Marine Re- search, St. Petersburg); FSM (Florida State Museum, University of Florida, Gainesville); LACM (Los Angeles County Museum of Natural History, Los Angeles); MCZ (Museum of Comparative Zoology, Harvard University, Cambridge); MNHN (Museum National d'Histoire Naturelle, Paris); TAMU (Invertebrate Collection, Texas A\&M University, College Station); UMML (Rosenstiel School of Marine and Atmospheric Sciences, University of Miami, Coral Gables); USNM (U.S. National Museum of Natural History, Washington).

\section{SYSTEMATICS}

\section{Family Trochidae}

Cataeginae new subfamily

Type genus: Cataegis new genus

Diagnosis: Shell non-umbilicate, with strong spiral cords, nacreous interior, oblique aperture, non-plicate columella, multispiral operculum.

Left gill bipectinate with long afferent membrane posterior to free tip. Snout expanded at tip; cephalic tentacles with broad bases, eyes on short peduncles; cephalic lappets lacking; epipodial tentacles small; left and right neck lobes well developed, finely fringed at edges; left neck lobe folded over, evidently capable of rolling to form incurrent siphon.

Radula lacking rachidian; lateral teeth 4 pairs, inner laterals fused, uncusped; second, third, and fourth laterals with simple, tapered, overhanging tips, shafts elongate with narrow frontal elements and large, triangular rear elements; inner edge of rear element interlocking with corresponding depression on outer edge of adjacent lateral tooth; latero-marginal plate not evident; marginals numerous, first marginal enlarged, second and third marginals decreasing in size, remaining marginals with sickle-shaped tips and up to 6 blunt denticles on each side of tip.

Discussion: Although shell characters are of minor importance in suprageneric classification of trochids, the combination of shell characters (strong spiral cords, lack 

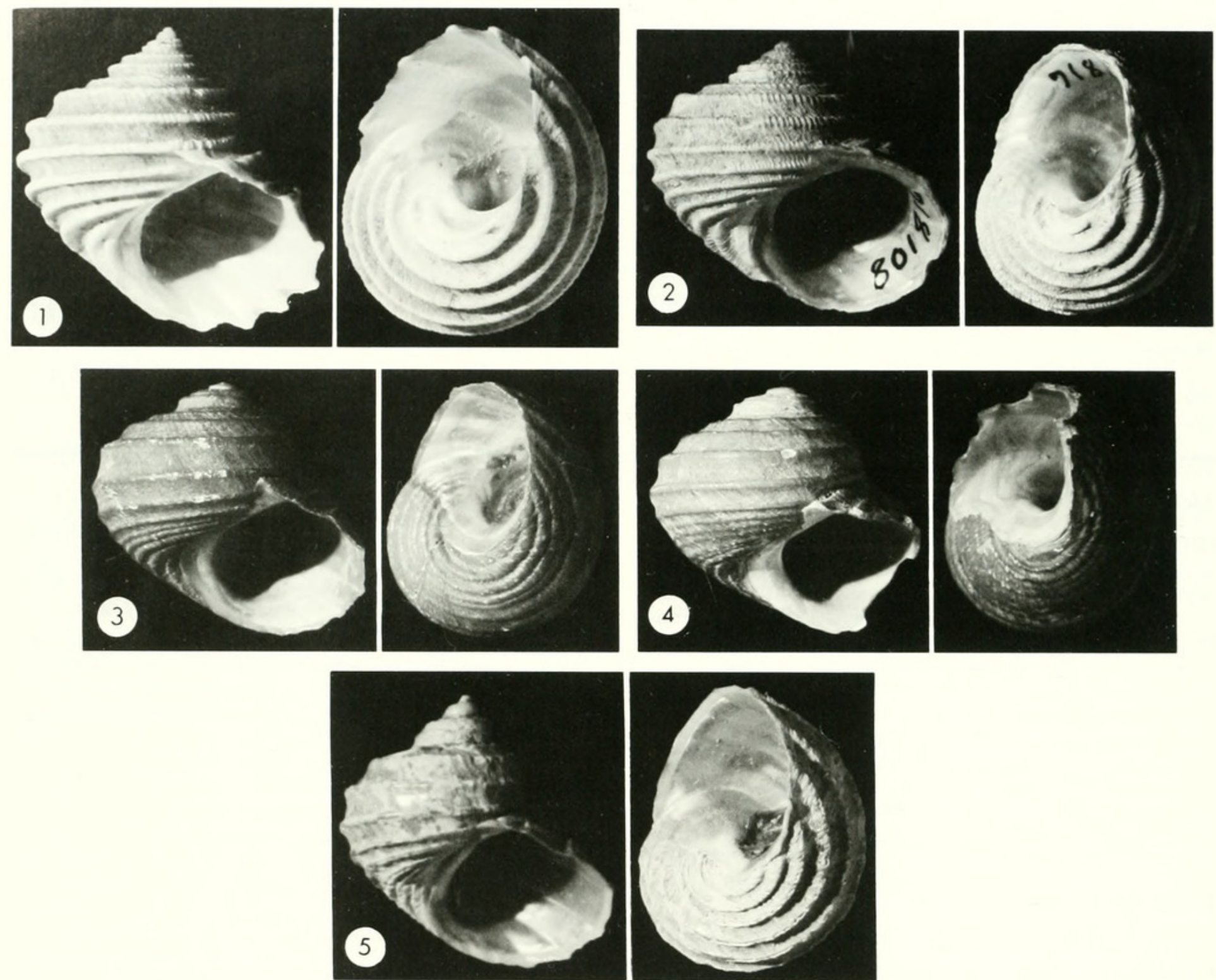

Figures 1-5. Shells of new species of Cataegis, apertural and basal views. 1, 2. Cataegis toreuta new species. 1. Holotype, off Colombia, USNM 784755, height 21.8 mm. 2. Paratype, off Biloxi, Mississippi, USNM 801816, height 19.3 mm. 3, 4. Cataegis meroglypta new species. 3. Holotype, off Mississippi River Delta, Louisiana, MNHN uncat., height 17.8 mm. 4. Paratype, off Colombia, USNM 784757, height 16.9 mm. 5. Cataegis celebesensis new species. Holotype, MNHN uncat., Makassar Strait, Celebes, Indonesia, height $20.4 \mathrm{~mm}$

of columellar plications, oblique, broadly expanding aperture) in Cataegis is unique.

Epipodial characters are those of generalized trochids in having well-developed left and right neck lobes, although most trochids have cephalic lappets and betterdeveloped epipodial tentacles. Most deeper water trochid genera are included within the broadly defined subfamily Margaritinae (as used by Keen in Moore, 1960); these genera have in common a thin shell and most lack columellar plications. On shell and external anatomical characters it seemed likely that Cataegis should be related to such margaritine genera as Cidarina Dall, 1909. McLean (1982) noted, however, that genera of the old group "Margaritinae" have a primitive gill structure in which the afferent membrane is short. Contrary to all xpectations for a deep-water genus, the gill structure of
Cataegis is advanced, with a long afferent membrane like that of genera of the subfamilies Monodontinae, Trochinae, Calliostomatinae, and Solariellinae (as used by Keen in Moore, 1960).

The new subfamilial classification of Trochidae to be introduced by Hickman and McLean (in preparation) is, in large part, based upon a discrete radular plan for each subfamily. The radula of Cataegis fits nowhere within this scheme but represents yet another unique plan. Although there are genera in which the rachidian is uncusped, no other trochid group completely lacks the rachidian tooth and no other group exhibits a fusion of the bases of the first pair of lateral teeth, forming a "central element" that replaces the rachidian. The interlocking of the laterals is also unique; other radular plans show interlocking of the lateral teeth in different ways (for 

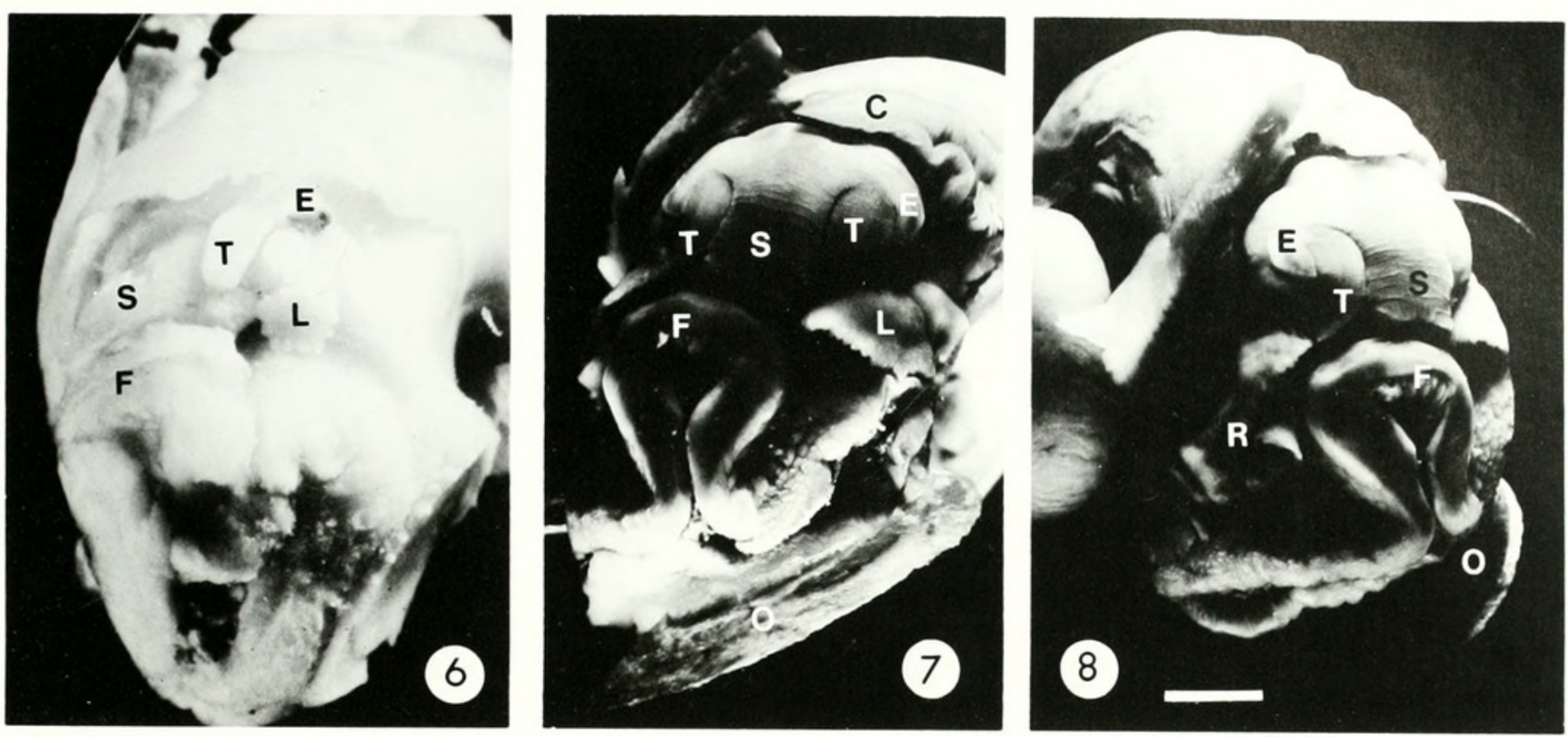

Figures 6-8. External anatomy of Cataegis, photographs of retracted bodies. 6. Cataegis toreuta new species (sta. P-388). 7, 8. Cataegis meroglypta new species (holotype). Bar $=2 \mathrm{~mm}$

C, ctenidium; E, eye; F, foot; L, left neck lobe; O, operculum; R, right neck lobe; S, snout; T, cephalic tentacle

discussion see Hickman, 1984). Enlargement of the first marginal is a character state of the Calliostomatinae, but other features of the radula and external anatomy of Calliostoma Swainson, 1840, are missing.

\section{Cataegis new genus}

Type species: Cataegis toreuta new species.

Diagnosis: Shell of moderate size (to about $25 \mathrm{~mm}$ in height), turbinate, slightly wider than high, non-umbilicate, with strong spiral sculpture; white under greenishbrown periostracum. Whorls well rounded, with about $7-12$ strong, irregularly rugose or finely nodose spiral cords; axial sculpture of nodes or limited to strong growth lines; base rounded, aperture oblique, circular, nacreous within; outer lip thin, fluted by spiral sculpture; columella smooth, thickened, evenly arcuate. Operculum corneous, thin, circular, multispiral, with central nucleus.

Characters of gill, external anatomy, and radula as described above under subfamilial diagnosis.

Distribution: Cataegis is known from the three new species here described: the type species $C$. toreuta, $C$. meroglypta (both known from contiguous continental slopes of the mainland extending from the Gulf of Mexico to Colombia), and C. celebesensis at similar depths from Indonesia. The existence of two Caribbean species plus C. celebesensis in the Indo-Pacific faunal province indicates that the distribution of the genus is Tethyan and at least Cretaceous in origin. Until continental slope depths of other regions of the world are adequately sampled, it is unknown whether the present distribution is that of a relict genus, although that is the most likely explanation. All records for this genus are from continental slope depths, suggesting that the genus survives in relatively deep water. This agrees with the conclusion of Jablonski et al. (1983) that evolutionary innovations arise in shallow water and survive extinction by retreating offshore to deeper water where conditions are more stable.

Gut contents of the specimen of Cataegis toreuta from which the radula was prepared (figures 9,10 ) included numerous pieces of plant remains identified as the Caribbean turtle grass, Thalassia testudinum, remains of which are common in the deep sea and continental slopes (for review see Wolff, 1979). The ready availability of this food may be a factor relating to the relatively large size of members of the genus. It lends further support to the hypothesis that the group originated in shallow water, the source of the food supply.

Etymology: Latin cataegis (from Greek kataigis), a feminine noun meaning hurricane or whirlwind, with reference to the strong spiral sculpture.

Cataegis toreuta new species

(figures 1, 2, 6, 9, 10)

Description: Shell (figures 1,2) attaining $24.6 \mathrm{~mm}$ in height, $25.1 \mathrm{~mm}$ in diameter, turbinate, non-umbilicate, rather thick and solid, white. Periostracum thin, deciduous, light brown. Protoconch diameter $400 \mu \mathrm{m}$. Teleoconch whorls 5 , rapidly expanding, last whorl well rounded. Spiral sculpture of 8-12 (usually 9) strong cords with broad, strongly concave interspaces; interspaces with fine 

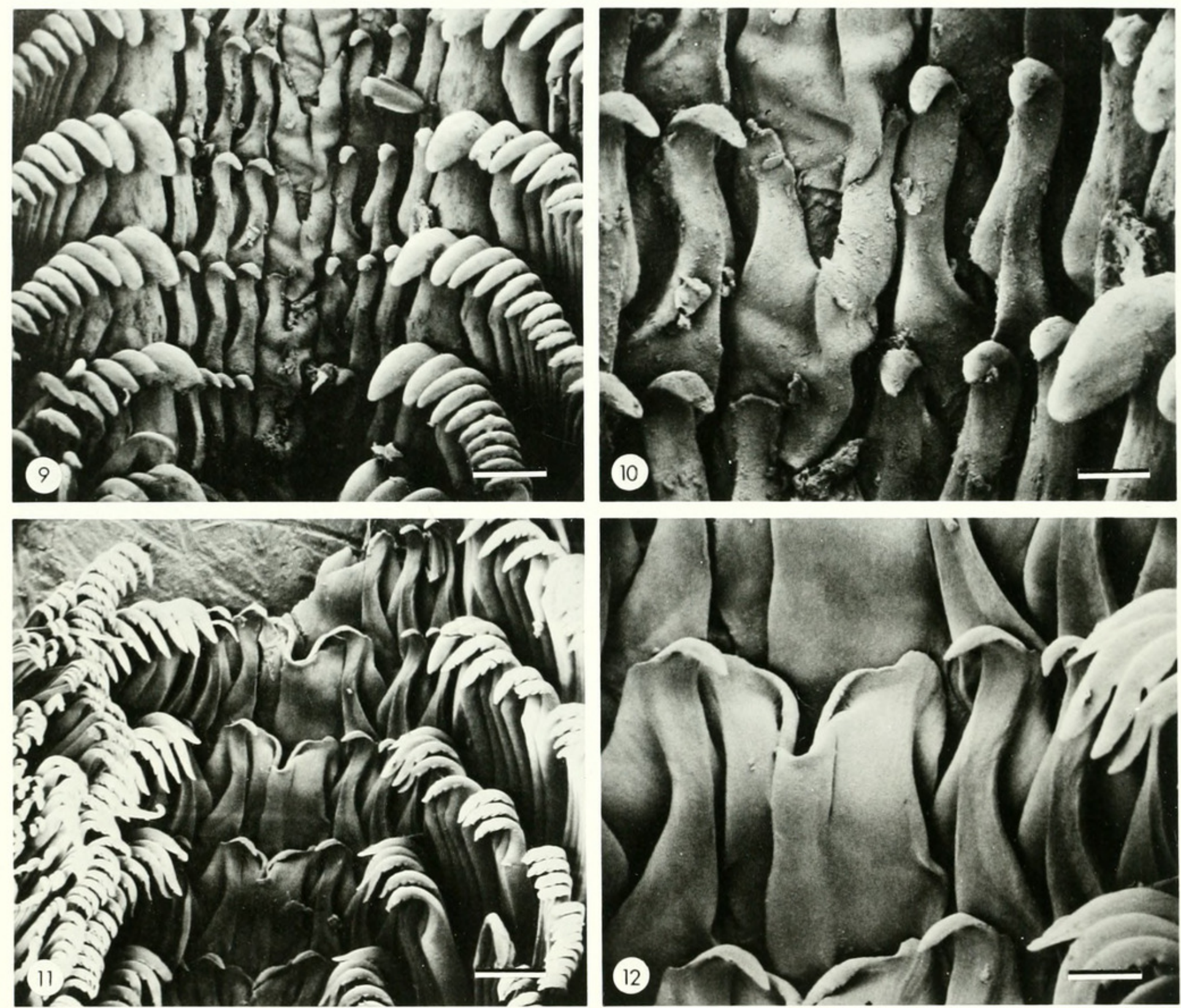

Figures 9-12. Radulae of Cataegis, SEM micrographs. 9, 10. Cataegis toreuta new species (sta. 71-A7-11), showing fused first laterals, second, third, and fourth laterals, enlarged first marginal and succeeding pairs of marginals (scale bar of $9=50 \mu \mathrm{m}$, of $10=20 \mu \mathrm{m}) .11,12$. Cataegis celebesensis new species (holotype), showing same features $(\mathrm{scale}$ bar of $11=50 \mu \mathrm{m}$, of $12=20$ $\mu \mathrm{m})$

intercalary spiral threads. Axial sculpture on second and third whorls of regularly spaced, oblique folds forming sharp nodes on crossing primary spirals; third to fifth whorls with close-set, irregular collabral growth lines forming low, sublamellar nodes on primary spiral cords. Base not distinct from rest of whorl, with umbilical depression. Aperture nearly circular, nacreous within; outer lip strongly prosocline, fluted by external sculpture; columella arcuate, thickened, smooth, with thin wash of nacre; inner lip reflected, thickened, usually concealing umbilical depression; parietal wall with thin porcelaneous callus. Operculum corneous, thin, amber, multispiral with numerous volutions.

Dimensions: Holotype: height $21.8 \mathrm{~mm}$, diameter 22.9 $\mathrm{mm}$; largest specimen: height $24.6 \mathrm{~mm}$, diameter 25.1 $\mathrm{mm}$.

Gill and external anatomy (figure 6) as described above under subfamily diagnosis.

Radula (figures 9,10 ) lacking rachidian; lateral teeth 4 pairs, first laterals fused at base, uncusped; second, third, and fourth laterals with simple, tapered, overhanging tips; shafts elongate with narrow frontal elements and large, triangular rear elements; inner edge of rear element interlocking with corresponding depression on outer edge of adjacent lateral tooth; latero-marginal plate not evident; marginals numerous, shaft of first marginal twice breadth of the second; second marginal twice thickness of third; remaining marginals decreasing in 
size, with sickle-shaped tips and up to 6 blunt denticles on each side of tapered tip.

Type locality: W of Punta Piedras, Colombia, $9^{\circ} 20.2^{\prime} \mathrm{N}$, $76^{\circ} 34.2^{\prime} \mathrm{W}, 933-961 \mathrm{~m}$

Type material: Holotype: USNM 784755, John Elliott Pillsbury sta. P-364, 10' otter trawl, July 13, 1966 (figure 1). Paratypes (by vessel and station number):

John Elliott Pillsbury sta. P-381, off Colombia, $10^{\circ} 17^{\prime} \mathrm{N}$, 7559.9' W, 733-604 m; 2 specimens, UMML 30.3420; 2 specimens, LACM 2264.

John Elliott Pillsbury sta. P-388, off Colombia, $10^{\circ} 16^{\prime} \mathrm{N}$, $76^{\circ} 03^{\prime} \mathrm{W}, 824-1,061 \mathrm{~m} ; 1$ specimen, UMML 30.3429

John Elliott Pillsbury sta. P-394, off Colombia, $9^{\circ} 28.6^{\prime} \mathrm{N}, 76^{\circ} 26.3^{\prime} \mathrm{W}, 421-641 \mathrm{~m} ; 4$ specimens, UMML 30.3498 .

John Elliott Pillsbury sta. P-407, off Colombia, $9^{\circ} 00.2^{\prime} \mathrm{N}, 77^{\circ} 25.3^{\prime} \mathrm{W}, 1,171-1,239 \mathrm{~m} ; 3$ specimens, USNM 784756; 2 specimens, MCZ 296111; 2 specimens, ASNP 359168; 2 specimens, FSBC I 31770 ; 2 specimens, UMML 30.3576.

John Elliott Pillsbury sta. P-413, off Colombia, $9^{\circ} 01.5^{\prime} \mathrm{N}, 76^{\circ} 53^{\prime} \mathrm{W}, 1,281-1,283 \mathrm{~m} ; 3$ specimens, UMML 30.3607

Oregon II sta. 4580 , off Biloxi, Mississippi, $29^{\circ} 06^{\prime} \mathrm{N}$, $88^{\circ} 06^{\prime} \mathrm{W}, 805 \mathrm{~m}$; 1 specimen, USNM 801816 (figure 2).

Oregon II sta. 11228, off Panama, $9^{\circ} 05^{\prime} \mathrm{N}, 81^{\circ} 18^{\prime} \mathrm{W}$, $594 \mathrm{~m} ; 7$ specimens, FSM 28719.

Oregon II sta. 39554, off Corpus Christi, Texas, $27^{\circ} 25.7^{\prime} \mathrm{N}, 95^{\circ} 54.2^{\prime} \mathrm{W}, 337-412 \mathrm{~m} ; 1$ specimen, FSM 40669 .

Alaminos sta. 68-A7-10A, off Pensacola, Florida, $29^{\circ} 15.5^{\prime} \mathrm{N}, 86^{\circ} 55^{\prime} \mathrm{W}, 541 \mathrm{~m}$; 1 specimen, MNHN uncat.

Alaminos sta. $68-\mathrm{A} 7-15 \mathrm{H}$, off Pensacola, Florida, $29^{\circ} 10.5^{\prime} \mathrm{N}, 87^{\circ} 16^{\prime} \mathrm{W}, 914 \mathrm{~m}$; 1 specimen, MNHN uncat.

Alaminos sta. 69-Al1-64, off Vera Cruz, Mexico, $19^{\circ} 28^{\prime} \mathrm{N}, 95^{\circ} 58^{\prime} \mathrm{W}, 384 \mathrm{~m} ; 1$ specimen, TAMU 4-1954.

Alaminos sta. 71-A7-11, off Brownsville, Texas, $26^{\circ} 32.3^{\prime} \mathrm{N}, 96^{\circ} 05^{\prime} \mathrm{W}, 636 \mathrm{~m}$; 1 specimen, MNHN uncat. (figures 9,10 , radula).

Alaminos sta. 71-A8-47, off Vera Cruz, Mexico, $21^{\circ} 35^{\prime} \mathrm{N}, 96^{\circ} 54.6^{\prime} \mathrm{W}, 937 \mathrm{~m}$; 1 specimen, MNHN uncat.

Distribution: Western Atlantic, off Pensacola, Florida, to Colombia, continental slope depths, 337-1,283 m.

Etymology: Greek toreuta, masculine noun in apposition, worker using a lathe.

Remarks: This is the best represented of the three species of Cataegis. It is the only species in which the nodose axial sculpture persists in later whorls. The radula differs from that of C. celebesensis in having the first marginals more prominent, and in more clearly indicating that the central element represents a fusion of the first lateral teeth (figure 10).
Cataegis meroglypta new species (figures $3,4,7,8$ )

Description: Shell (figures 3, 4) attaining at least 17.8 $\mathrm{mm}$ in height, $18.9 \mathrm{~mm}$ in diameter; turbinate, rather thick and solid, white. Periostracum thick, brown to greenish-brown. Protoconch unknown (eroded on all specimens). Teleoconch whorls 3.5, rapidly expanding, last whorl well rounded. Spiral sculpture of 4 or 5 strong spiral cords adapically and 6 or 7 on base; cords irregularly rugose, but not distinctly beaded; interspaces between primary spiral cords smooth or bearing as many as 5 weak spiral threads. Axial sculpture on first 2 whorls of low, oblique folds radiating from suture to first primary cord; later whorls with low, irregular, rugose, collabral growth lines. Base not distinct from rest of whorl, with central umbilical depression. Aperture nearly circular, nacreous within; outer lip strongly prosocline, slightly fluted by external spirals; columella arcuate, thickened, smooth, with thin wash of nacre; inner lip reflected, forming rather thick, porcelaneous callus concealing most of umbilical depression; parietal wall with thin wash of porcelaneous callus. Operculum corneous, thin, amber, multispiral with numerous volutions.

Dimensions: Holotype: height $17.8 \mathrm{~mm}$, diameter 18.9 $\mathrm{mm}$; paratype: height $16.9 \mathrm{~mm}$, diameter $18.4 \mathrm{~mm}$.

Gill and external anatomy (figures 7,8 ) as described above under subfamily diagnosis.

Radula not examined (body of holotype maintained intact)

Type locality: S of Mississippi River Delta, Louisiana, $27^{\circ} 49^{\prime} \mathrm{N}, 90^{\circ} 07^{\prime} \mathrm{W}, 845-858 \mathrm{~m}$.

Type material: Holotype: MNHN uncat, LGL Cruise 1-MMS-C3 (figure 3). Paratypes (empty shells): John Elliott Pillsbury sta. P-394, W of Punta Piedras, Colombia, $9^{\circ} 28.6^{\prime} \mathrm{N}, 76^{\circ} 26.3^{\prime} \mathrm{W}, 421-641 \mathrm{~m}$; l specimen, USNM 784757 (figure 4); 2 specimens +1 fragment, UMML 30.3499 .

Distribution: Western Atlantic; Louisiana to Colombia, continental slope depths, 421-858 m.

Etymology: Adjective derived from Greek: meros, part, and glyptos, carved

Remarks: Cataegis meroglypta differs from C. toreuta new species in having fewer, weaker spiral cords that are irregularly rugose rather than discretely nodulose, weaker spiral threads between the adapical cords, and a thicker, darker periostracum.

Cataegis celebesensis new species

(figures 5, 11, 12)

Description: Shell (figure 5) attaining $20.4 \mathrm{~mm}$ in height, $20.3 \mathrm{~mm}$ in diameter, turbinate, non-umbilicate, rather thick and solid, white. Periostracum thin, deciduous, light brown. Protoconch unknown (eroded in holotype). Teleoconch whorls 4 , rapidly expanding, last whorl well rounded. Spiral sculpture of 8 strong cords with broad, 
strongly concave interspaces; fine intercalary spiral threads present in interspaces. Axial sculpture of irregular rugosities on spiral cords and close-set, irregular collabral growth lines. Base not distinct from rest of whorl. Aperture nearly circular, nacreous within; outer lip strongly prosocline, fluted by external sculpture; columella arcuate, thickened, smooth, with thin wash of nacre; inner lip reflected, raised over umbilical depression; parietal wall with thin porcelaneous callus. Operculum corneous, thin, amber, multispiral with numerous volutions.

Dimensions: Holotype: height $20.4 \mathrm{~mm}$, diameter 20.3 $\mathrm{mm}$.

Gill and external anatomy as described above under subfamily diagnosis.

Radula (figures 11, 12) lacking rachidian; lateral teeth 4 pairs, inner laterals uncusped, fused at base, fused area buckling forward; second, third, and fourth laterals with simple, tapering, overhanging cusps; shafts elongate with narrow elements and larger, triangular rear elements; inner edge of rear element interlocking with corresponding depression on outer edge of adjacent lateral tooth; latero-marginal plate not evident; marginals numerous, innermost marginals slightly larger than remaining marginals, with sickle-shaped tips and up to 6 blunt denticles on each side of tip.

Type locality: Makassar Strait, off W side Minahassa Peninsula, Celebes, Indonesia, $0^{\circ} 05^{\prime} \mathrm{S}, 119^{\circ} 48^{\prime} \mathrm{E}, 1,080 \mathrm{~m}$.

Type material: Holotype: MNHN uncat, Corindon Expedition sta. 231 (figure 5). Paratype (dry with operculum in place): Albatross sta. 5668, Makassar Strait, Indonesia, $2^{\circ} 28^{\prime} \mathrm{S}, 118^{\circ} 49^{\prime} \mathrm{E}, 1,647 \mathrm{~m}$; 1 specimen, USNM 239507.

Distribution: Makassar Strait, Indonesia, 1,080-1,647 $\mathrm{m}$.

Etymology: The name is an adjective derived from Celebes Island.

Remarks: Cataegis celebesensis differs from C. toreuta in having a higher profile of fewer whorls and in lacking the pronounced axial nodes of that species. The radula of $C$. celebesensis has first marginals that are not as enlarged as those of C. toreuta. The illustrated preparation of the radula of the holotype shows the fused first lateral teeth in nearly perfect condition (figure 12). The regular outline of the first laterals in successive rows shows that cusps were not formed and eliminates the possibility that the cusps were simply worn down.

\section{ACKNOWLEDGEMENTS}

We thank the following curators for access to material in collections under their care: P. Bouchet (MNHN); R. S. Houbrick and the late J. Rosewater (USNM); G. L. Voss (UMML); F. C. Thompson (FSM); and L. Pequenat (formerly TAMU). Photographs of the bodies were made by B. C. Draper, volunteer at the LACM. SEM micrographs of radulae were made at the Center for Electron Microscopy and Microanalysis, University of Southern California, Los Angeles, with the assistance of C. Coney, LACM. We thank C. S. Hickman, University of California, Berkeley, for helpful commentary.

\section{LITERATURE CITED}

Hickman, C. S. 1984. Implications of radular tooth-row functional integration for archaeogastropod systematics. Malacologia 25:143-160.

Jablonski, D., J. J. Sepkoski, Jr., D. J. Bottjer, and P. M. Sheehan. 1983. Onshore-offshore patterns in the evolution of Phanerozoic shelf communities. Science 222:1123-1125.

Keen, A. M. 1960. [Cenozoic Archaeogastropoda.] In: Moore, R. C. (ed.). Treatise on invertebrate paleontology. Part I, Mollusca 1, Geological Society of America and University of Kansas Press, Lawrence, xii +351 p.

Marshall, B. A. 1979. The Trochidae and Turbinidae of the Kermadec Ridge (Mollusca: Gastropoda). New Zealand Journal of Zoology 6:521-552.

McLean, J. H. 1982. Importance of gill structure in trochacean classification. The Western Society of Malacologists, Annual Report 14:11

Wolff, T. 1979. Macrofaunal utilization of plant remains in the deep sea. Sarsia 64:117-136. 


\section{$2 \mathrm{BHL}$ Biodiversity Heritage Library}

1987. "Cataegis, new genus of three new species from the continental slope (Trochidae: Cataeginae new subfamily)." The Nautilus 101, 111-116. https://doi.org/10.5962/bhl.part.17408.

View This Item Online: https://www.biodiversitylibrary.org/item/33813

DOI: https://doi.org/10.5962/bhl.part.17408

Permalink: https://www.biodiversitylibrary.org/partpdf/17408

\section{Holding Institution}

MBLWHOI Library

\section{Sponsored by}

MBLWHOI Library

\section{Copyright \& Reuse}

Copyright Status: In copyright. Digitized with the permission of the rights holder.

Rights Holder: Bailey-Matthews National Shell Museum

License: http://creativecommons.org/licenses/by-nc-sa/3.0/

Rights: https://biodiversitylibrary.org/permissions

This document was created from content at the Biodiversity Heritage Library, the world's largest open access digital library for biodiversity literature and archives. Visit BHL at https://www.biodiversitylibrary.org. 